\title{
Commonplace
}

\section{Distributed Open \\ Collaborative Scholarship}

\section{Sarah Kember ${ }^{1}$}

${ }^{1}$ Professor of New Technologies of Communication, Goldsmiths; Director, Goldsmiths Press

Published on: Mar 15, 2020

DOI: $10.21428 / 6 f f d 8432 . f d f 89 d 72$

License: Creative Commons Attribution 4.0 International License (CC-BY 4.0). 


\section{Introduction}

Technologies of communication, from the printing press to the digital platform contribute significantly to the transformation of knowledge. Digital technology is in the process of reshaping teaching and learning, research and publishing. Key features of the changing knowledge landscape include: distance learning, MOOCS, the development of open educational resources (including video, podcasts and other media), $\underline{1}$ open access online courses and textbooks (MIT Open Courseware, Cambridge Core), the emergence of new scholar-led and university presses and the development of new disciplines such as digital humanities.

Over the last forty years, taking the 1980s and the development of the personal computer as a watershed in the development of digital communications, the pace of change has been relatively slow due to a combination of institutional and infrastructural factors. Transformational practices have remained marginal and incremental, introducing, for example, the digital classroom as an adjunct to the conventional lecture and seminar and subordinating open access publications to more traditional journal articles and monographs. However, in conjunction with the consolidation of a neoliberal model for higher education - characterized by funding cuts, rising tuition fees, casual and precarious labor, the marketization of courses, institutional and individual competition, the conflation of training and education, consumer relations between academics and students, instrumental research (impact), increased used of metrics and the development of an audit culture (UK) - technology is now accelerating the potential for change.

In a neoliberal context, market values dominate knowledge and culture as well as the economy, and, in the academic context values are currently limited to efficiency, transparency and compliance. Technology promotes efficiency by, for example, massively expanding the consumer base for marketable courses and academics (MOOCS); standardizing and systematizing research outputs (templates, protocols) and automating publishing processes and practices such as editing and peer review. Technology promotes transparency by implementing open access policies and mandates and through new forms of tracking and measurement from digital object identifiers (DOIs) to article based metrics. Various forms of monitoring, audit and surveillance, within what is rapidly becoming an obligatory digital enclosure, enable compliance to become more widespread. 
The entanglement of technology and neoliberalism is detrimental to the present and future flourishing of knowledge in as far as knowledge is restricted and reduced to a limited set of values. These values are designed by and for a marketplace that is conflated with, but by no means equivalent to any notion of the public good. By extension, the first step towards reestablishing knowledge as a public good, and specifically as an urgently needed form of social and environmental justice involves disentangling technology from the limiting values of efficiency, transparency and compliance and promoting instead, values such as equality, diversity, care and inclusion. Ultimately, a new, post-neoliberal, ecological economics of scholarly publishing, teaching and research (representing the whole ecology of knowledge) should be founded on cooperation, collaboration and sustainability instead of growth and competition; responsible house-holding, or careful management of the environment, rather than the extraction of resource and exploitation of labor; and on the fair sharing of finite resources (labor and materials).

Distributed Open Collaborative Scholarship (DOCS) is a major new initiative that aims to redirect the technologization of knowledge by building structures (disciplines, practices, ethics) and infrastructures around a new ecological economics of teaching and learning, research and publishing. It builds on existing interventions such as FemTechNet, a Distributed Open Collaborative Course for students, scholars and artists working on feminist science and technology studies $\underline{2}$; Fembot/Ada, a research collective and associated open access publication $\underline{3}$; Goldsmiths Press, a new university press in the UK, dedicated to challenging the restrictions of neoliberal scholarship; $\underline{4}$ Humanities Commons, a US project bringing together open access scholarship and teaching materials in the humanities $\underline{5}$ and open access platforms such as arXiv.org and $\underline{\text { SOCarXiv. }} . \underline{6}$

DOCS is a necessary addition to the current landscape because much of the current activity either sits within or fails to challenge neoliberal values that apply across the entire ecology of teaching and learning, research and publishing and incorporate both the sciences and humanities. Neoliberal economies promote and support open science at the expense of open humanities and globally, Arts, Humanities and Social Science disciplines are under threat. The development of commercial platform based publishing and scholarship, such as academia.edu, tends to be parasitic on both publishers and the academy, extracting published research with no reciprocal financial contribution. Moreover, by selling data based on research hits and trends, it represents something like the Twitter model for the future dystopia of scholarly communications 
in which the value of knowledge itself, and its social and environmental agency is subordinated to its economic value. Commercial platforms represent the next phase in the capitalization of knowledge and tend towards replacing old monopolies for new, the giants of commercial journal publishing with tech giants such as Amazon and Google.

\section{Distributed}

Distributed structures and infrastructures of knowledge, that work transversally across disciplines, research cultures (notably Science, Technology, Engineering and Math or STEM and Arts, Humanities and Social Sciences - AHSS), institutions and organizations (such as universities, archives, museums, galleries, publishers and noncommercial platforms) can, if they scale sufficiently, remain open sourced and develop community forms of governance, provide an antidote to the rise of knowledge monopolies.

Distributed models do not seek to break up or disrupt for example, the vertical integration of publishing houses in favor of a range of outsourced, user-centric publishing services that in any case will transit from an open competitive market towards a more monopolistic one. $\underline{7}$ Rather, they seek to promote collaboration between mission-driven university press publishers, their respective institutions of teaching, learning and research and allied organizations in order to sustain and enable a more diverse ecology of public knowledge, necessary to fulfill the goals of social and environmental justice.

Neoliberal forms of knowledge, driven by market values, are narrowing, becoming systematized as well as standardized by disciplines, discourses and norms of communication. The process of systematization is both rapid and largely invisible, being a facet of technological infrastructures and of market-based values that are working their way "upstream" in the research cycle, redesigning knowledge, automatically pre-fitting it for an economy based on efficiency, competition, performance, growth, engagement or impact. The drift towards fully tech based, platform publishing captures the ideology of automation. In addition to automated text and data mining and automated peer review selection (in STEM) there is also the prospect of machine-generated text.

Machine-generated text is produced using the same software as deepfake videos. Generative adversarial networks or GANs are composed of two neural networks, one generator and one discriminator working against each other in order to create new 
data, stories, images or text. Given a specific training set, the discriminator will get better at distinguishing fake from real, so the generator has to improve the plausibility of its output. What is interesting here is the internalization and systematization of an adversarial process that is creative but ultimately indiscriminate, one that will give rise to technological forms of knowledge that are self-enclosed, self-generating and decontextualized. Where improved regulatory frameworks and digital literacy have a role to play, it is worth recalling a long cultural history of fakes and hoaxes, many of which have been satirical and politicized and the fact that machine, like human agency is relational, not autonomous and often - truly - antagonistic. GANS, however enclosed, are unlikely to remain unopposed.

Writing and publishing technologies are evolving, but automation remains a longstanding reach that will always exceed its grasp. While machine-generated texts and images still reside in the uncanny valley (that is, close, but not quite convincing), the ideology of automation promises to make scholarship homogeneous and systematic. It may never actually do this, but, without intervention, it will do something like this, because the technological imaginary works performatively, contributing to the construction of its own vision.

Distributed models are both machinic and humanistic, recognizing the relational, or transversal nature of both machine and human forms of agency. They are collaborative across all scales of knowledge and communication, applying to institutions, disciplines and (post-human) subjects. The value of distributed structures and infrastructures should be understood in strategic rather than essentialist terms, not as the ontology of digital technology but rather as a means of mutual support and symbiotic evolution.

\section{Open}

Open access is, but is not simply about making publicly funded research free to use and available for reuse in the service of the public good. For one thing, it is clear that commercial licenses are preferred or mandated and humanities scholars have argued that the obligation to be open falls asymmetrically on the public/Higher Education and private sector, so that Goldsmiths, for example, is obliged to be open and Google, for example, is not. The sociologist John Holmwood regards open access policy as a form of commercial enclosure and privatization of education $\underline{8}$ and the British digital humanities scholar David Berry points to the fact that open access is a means of creating public subsidy for the private sectors' use of university research output without any reciprocal contribution. $\underline{9}$ 
The dominant model of open access is neoliberal and contested within the academy, especially in AHSS where the costs of publishing are higher (because book processing charges apply) and the funding, relative to STEM, is minimal. In the absence of wide scale public funding that could sustain a multi-disciplinary global industry, the costs of publishing will be further deferred to the academy, resulting in increased inequalities between and within universities. The current move to transformative agreements (publish and read, read and publish deals) either maintain or enhance the power of large commercial publishers and, while they assume a degree of institutional cooperation, are by no means promoting collaboration, inclusiveness or diversity.

By adding costs to institutions that, in many cases, are already struggling in a competitive, Darwinian environment, it is likely that open access mandates (especially stringent in the UK) will further the cause of platform publishing with its stripped down, editorially light, low cost process of uploading preprints and awaiting postpublication peer review. This is a model that works for STEM fields and STEM temporalities (the need to share research openly, widely and rapidly, especially in the medical and life sciences) but has not yet been refitted for AHSS where the research process takes longer and tends to be less urgent, where data is not extractable from discourse and is often still presented in the form of print books, which require more conventional modes of dissemination.

The use of book processing charges for AHSS, with no business model or funding to support the transition from a pay to read to a pay to publish economy, will lead to reduced output and a future in which the majority of AHSS scholars, especially those who are less privileged and protected (such as early career and retired academics, women and scholars of color), will either not publish or be obliged to self-publish on Amazon. At a time when universities across the global North are seeking to decolonize the curriculum, the neoliberal model of open access will lead to narrower, more normative publishing practices that will directly impact and impoverish teaching and learning.

However, a distributed network oriented to the future flourishing of public knowledge might integrate open access for both STEM and AHSS, preserving and developing platform and print models, sharing costs, cross-subsidizing, working with funders, building infrastructures and exploring post- or supra-disciplinary knowledge forms necessary for today's major challenges from poverty and disease to inequality of opportunity, homelessness, displacement and global warming. DOCS is consistent with, 
and can help to realize a post-viral ecological economics of knowledge that relies less on face-to-face contact and international travel.

Unfunded, underfunded and unsustainable open access mandates will exacerbate existing inequalities, but a wide range of stakeholders might work together to share costs and promote recovery and diversity projects such as Reanimate $\underline{10}$ that will contribute to decolonizing the canon and opening up or reevaluating scholarly publishing and communications, including with respect to access and accessibility as well as different understandings of impact, engagement, monitoring and measurement. Against a narrow and reductionist neoliberal investment in metrics, there is an opportunity to reconsider what really counts as scholarship, who counts in it, and what it can still usefully do as a form of social and environmental intervention.

\section{Collaborative}

Collaboration is a necessary feature of distributed structures and infrastructures and a strategic manifestation and development of the idea of the commons. Creative Commons remains an important intervention in copyright, providing a wide range of commercial and non-commercial licenses that facilitate legal sharing and reuse of creative works. In an increasingly neoliberal culture of knowledge and communication, licenses and contracts oriented to commercialization are preferred or mandated and it becomes necessary to retrieve and reactivate an ethic of sharing from an economy of extraction and exploitation.

DOCS does not idealize the commons but recognizes that there are asymmetries of power and investment that can nevertheless produce meaningful forms of sharing and cooperation. The underlying assumption is one of heterogeneity rather than homogeneity, the mutual interest of multiple stakeholders rather than (pre-existing) communities of interest.

DOCS takes a less reformative, more critical and evaluative approach to international copyright law and open access policy. It builds on insights from, for example, feminist legal scholars who assert the relational, or dynamic, rather than autonomous identity of the legal subject $\underline{11}$ and feminist philosophers who regard the subject and object of knowledge as collaborative and constitutive, as the 'stuff of the world, accountable to multiple constituencies, not just the academic community' $\underline{12}$

Collaboration is key to opening knowledge to multiple constituencies and to what the scholar Donna Haraway refers to as strategies of re-worlding. $\underline{13}$ It works along the 
chain of epistemology, ontology, ethics and organization and at the level of structure and infrastructure in order to build alternative (post-human, post-disciplinary, embodied and situated, multiply accountable) forms of knowledge as the building blocks or stuff of future worlds.

\section{Scholarship}

The entanglement of technology and neoliberalism, along with widespread populism and anti-intellectualism inhibits the future flourishing of expert knowledge and scholarship. While there are important arguments in defense of knowledge and Higher Education $\frac{14}{}$ there is also an opportunity for re-evaluating and for asking what counts as scholarship - against a reductionist and instrumental culture of metrics - who counts in it, and what knowledge can and must do as an agent of world-making.

A more collaborative and open accounting of knowledge might do more to incorporate creative practice (accessing affective and imaginative dimensions of knowledge) and integrate students and researchers as co-producers of knowledge. It would build on new (post) disciplines such as digital, environmental and medical humanities and develop an agenda for equality, diversity and inclusion that works across publishing and the academy, STEM and AHSS.

DOCS explores post-disciplinarity as the question of how disparate knowledge practices interact and interoperate $\frac{15}{15}$ a form of synthesis $\underline{16}$ that might be less about consensus and integration than antagonism and decision-making. $\frac{17}{17}$ The ethics of decision-making is central to the re-evaluation of scholarship as a process of world building. The need for such decision-making is urgent, but this does not pertain to current discussions about fast and slow scholarship. While it is necessary to move beyond commercial and audit imperatives of increased productivity, efficiency and so on, slowing scholarship down is an understandable reaction, but not a critique or intervention. The question of knowledge is not one of speed as much as values and agency.

DOCS also addresses the need for more equitable, less normative scholarly practices such as citation and peer review and an ethics of knowledge that combines standards and codes of practice with a recognition that knowledge is contextual, embodied and co-produced by knowing subjects who are always thinking and being in a dynamic relation with others. 
What then might collaborative, relational scholarship look like? What new structures of knowledge do extended scholarly relations imply? What new modes, forms and styles?

DOCS is guided by principles of knowledge such as verification, experimentation, embodiment and situation. Situated knowledge is knowledge as, not just of the world. It is a form of world making that is ethically underwritten by virtue of being embodied. The epistemological basis of DOCS is less about what knowledge is or should be in a prescriptive or predictive sense, but to paraphrase the philosopher Hélène Cixous, what it can still do.

Rather than disrupt the academy through reformist and neoliberal policies such as open access, what transformations might occur both within and between institutions? Is the question of the post neoliberal university one of realizing new collaborative infrastructures, new knowledge structures and always already new relational entities (student-scholar-publisher....)?

\section{Conclusion}

the first step towards reestablishing knowledge as a public good, and specifically as an urgently needed form of social and environmental justice involves disentangling technology from the limiting values of efficiency, transparency and compliance and promoting instead, values such as equality, diversity, care and inclusion

Open access research will become embedded in invisible or black-boxed information infrastructures, automated systems that standardize and homogenize output and smart environments that embed inequalities at a representational and algorithmic level. $\underline{18}$ China's stated intention to link international open research to the competitive development of smart industries and smart societies $\underline{19}$ also raises questions about freedom of speech. Research will be offered as yet more content, available immediately, anytime and anywhere, tailored to individuals and embedded in smart materials. But who are the providers of open access, which, unfunded or underfunded, will rely even more on an economy of free labor? Who pays for open access, and who are the principle beneficiaries? The short answer of course, is the usual suspects and this demands a global intervention that foregrounds values of equality, diversity, care and inclusion.

At present little data exists on the demographics of authors in academic publishing, but what information there is suggests poor levels of diversity, potentially reflecting 
poor inclusivity in both publishing and academia. New and established university presses could work collaboratively across publishing and the academy in order to revisit shared missions and re-evaluate equity in scholarly communications. Such a project, feasible over the next 5 years, would build on existing standards and resources, such as those provided by the Association of University Presses $\underline{20}$ by working across publishing and the academy, so integrating scholarly research and activity in cognate areas within the host institutions; combining STEM and AHSS perspectives; embedding values in scholarly practices and assessment such as peer review, citation, metrics, impact and engagement and providing a roadmap for publishers and universities derived from the perspectives of those who study and experience inequality.

A consortium of UK university presses (Cambridge, Bristol, Liverpool, Westminster and Goldsmiths) is in the process of developing a project proposal (Re-evaluating diversity and inclusion in scholarly research and publishing: what counts and who counts?) that will extend to the US via MIT Press/MIT and the Knowledge Futures Group.

Ultimately, a new, post-neoliberal, ecological economics of scholarly publishing, teaching and research (representing the whole ecology of knowledge) should be founded on cooperation, collaboration and sustainability instead of growth and competition; responsible house-holding rather than the extraction of resource and exploitation of labor; and on the fair sharing of finite resources (labor and materials).

The long-term goal of DOCS is to establish a post-neoliberal ecological economics of publishing, teaching and research by building, demonstrating and exemplifying the relevant structures (disciplines, practices, principles, values, ethics) and infrastructures. Cross-institutional collaboration is key to a post-neoliberal ecological economics of scholarly publishing and communications. There are already a number of collaborative ventures from $\underline{\text { COPIM }}$ in the UK $\underline{21}$, to $\underline{\text { Coko }}$ in the US $\underline{22}$ and $\underline{\text { AmeliCA }}$ across Latin America $\underline{23}$. Generally concerned with implementing open science or humanities agendas, none at present work across science and the humanities and across publishing and the academy in order to reevaluate and reorganize scholarly communications. Knowledge Futures Group ( $\underline{\mathrm{KFG}}$ ), a global project based on open research and cross-institutionally governed infrastructures, $\underline{24}$ in conjunction with MIT's Open 2020 initiative in teaching and learning $\underline{25}$ has the potential to fulfill many of the short and long-term goals of DOCS. A joint declaration by Amy Brand, Director of The MIT Press and co-founder of KFG and Sarah Kember, Director of Goldsmiths 
Press and Professor of New Technologies of Communication at Goldsmiths is expected to inaugurate wider institutional investment in KFG and the goals outlined in this paper.

Sarah Kember

March 2020

\section{About the Author}

Sarah Kember is a writer, publisher and academic. She is Professor of New Technologies of Communication at Goldsmiths, and Director of Goldsmiths Press, the UK's first green open access university press monograph publisher (launched in 2016). Her research includes feminist studies of media, science and technology. Recent publications include iMedia. The gendering of objects, environments and smart materials (Palgrave, 2016), Whose Book is it Anyway? A view from elsewhere on publishing, copyright and creativity (Open Book Publishers, 2019) and the co-authored monograph Furious. Technological Feminism and Digital Futures (Pluto Press, 2020). With Janis Jefferies, Sarah Kember was co-PI of an RCUK funded project on digital publishing ('Whose Book Is It Anyway?' 2012-16), part of CREATe (Centre for Creativity, Copyright, Regulation, Enterprise and Technology). Kember is a critical advocate and experimenter with open access, publishing critiques such as 'Why Write? Feminism, Publishing and the Politics of Communication' and 'Why_Publish?' alongside ambiguous works of open fact/fiction such as Astrobiology and the Search for Life on

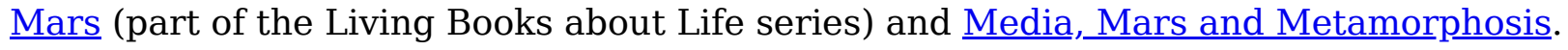

\section{Footnotes}

1. http://www.openculture.com/2016/10/new-handbook-for-educators-explains-howto-produce-distribute-free-video-for-the-world.html $\subseteq$

2. https://femtechnet.org/about/ $\triangleq$

3. https://fembot.adanewmedia.org $L \boxminus$

4. https://www.gold.ac.uk/goldsmiths-press/

5. https://hcommons.org $/ \boxminus$

6. 
https://socopen.org/welcome/

https://arxiv.org/

7. See Steven A. Hill 'Decoupling the academic book'

https://onlinelibrary.wiley.com/doi/full/10.1002/leap.1201

8. https://www.radicalphilosophy.com/commentary/commercial-enclosure $ヒ$

9. 'The Uses of Open Access', STUNLAW. Philosophy and Critique for a Digital Age, February 16, $2019 \boxminus$

10. http://reanimatepublishing.org $L \leftrightharpoons$

11.

Craig, C. Turcotte, J. F. and Coombe, J. (2011) 'What's Feminist about Open Access? A Relational Approach to Copyright in the Academy', feminists@law 1.1, http://journals.kent.ac.uk/kent/index.php/feministsatla w/article/view/7/54

Craig, C. J. (2011) 'Introduction - Copyright, Communication \& Culture:

Towards a Relational Theory of Copyright Law', Comparative Research in Law \& Political Economy. Research Paper No.

23/2011, https://digitalcommons.osgoode.yorku.ca/cgi/clpe/61

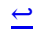

12. Braidotti, R. (2019) Posthuman Knowledge, Cambridge: Polity Press: $86 \boxminus$ 13. Haraway, Donna J. (2016) Staying with the Trouble, Durham and London: Duke University Press $\subseteq$

14.

https://www.aaup.org/report/defense-knowledge-and-higher-education

Back, L. (2016) Academic Diary. Or Why Higher Education Still Matters, London: Goldsmiths Press $\leftrightarrows$

15. Wark, M. (2015) Molecular Red. Theory for the Anthropocene, London and New York: Verso $\Xi$

16. Haraway, Donna J. (2016) Staying with the Trouble, Durham and London: Duke University Press $\subseteq$ 
17. Bassett, C. Kember, S. and O’Riordan, K. (2020) Furious. Technological Feminism and Digital Futures, London: Pluto Press $\leftrightarrows$

18.

Kember, S. (2016) iMedia. The gendering of objects, environments and smart materials, London: Palgrave Macmillan

Noble, S.U. (2018) Algorithms of Oppression, New York: NYU Press $\triangleq$

19. https://poynder.blog $\underline{\text { spot.com/ }} \triangleq$

20. http://www.aupresses.org/resources/for-scholarly-publishers/diversity-resources $\Xi$

21. https://re.ukri.org/news-events-publications/news/re-awards-2-2m-to-project-toimprove-open-access-publishing $/ \in$

22. https://coko.foundation/ $\leftrightarrows$

23. http://amelica.org/index.php/en/home/ $\leftrightarrows$

24. https://www.knowledgefutures.org $/ \oplus$

25.

https://wikis.mit.edu/confluence/display/open2020/Open+2020+Working+Group+Ho $\underline{\text { me }} \subseteq$ 